\title{
The Effects of Using Jigsaw Method Based on Cooperative Learning Model in the Undergraduate Science Laboratory Practices
}

\author{
Ataman Karacop \\ Department of Elementary Science Education, Education Faculty, Kafkas University, Turkey
}

Copyright $\bigcirc 2017$ by authors, all rights reserved. Authors agree that this article remains permanently open access under the terms of the Creative Commons Attribution License 4.0 International License

\begin{abstract}
The main aim of the present study is to determine the influence of a Jigsaw method based on cooperative learning and a confirmatory laboratory method on prospective science teachers' achievements of physics in science teaching laboratory practice courses. The sample of this study consisted of 33 female and 15 male third-grade prospective science teachers (6th term) who attended science teaching laboratory practices course in the 2014-2015 academic year. In the research, science teaching laboratory practices course was carried out in accordance with a Jigsaw method based on cooperative learning in an experimental group and a confirmatory laboratory method in a control group. Following the treatment, Science Laboratory Physic Achievement Test (SLPAT) was administered as the post-test. The data obtained with the instruments were evaluated using descriptive statistics, independent samples t-test, and ANCOVA. The results indicated that the student teachers had higher levels of achievement in physics topics which were taught through the Jigsaw method based on cooperative learning than through a confirmatory laboratory method. In addition, according to the SLPAT results, students' high levels of misunderstanding revealed that there were problems in the teaching process of physics concepts. It was determined that the student teachers in the research groups had conceptual misunderstandings about sound, electricity, magnetism, light and optics issues. Based on the applications performed in this study, the original Jigsaw was adapted to science laboratory applications as an alternative to the existing Jigsaw techniques in the literature. With similar efforts, the experiences of prospective science teachers can be enhanced for implementing modern teaching methods in their respective areas in the pre-service period. Thus, the provision of professional development of the pre-service science teachers can be supported.
\end{abstract}

Keywords Science Laboratory, Cooperative Learning, Jigsaw Method, Physics Topics

\section{Introduction}

Science, particularly the knowledge of physics topics, is an important part of the development of science and technology. Applications of physics have an important place in our daily lives and these applications provide economical and industrial developments in many countries of the world. Improvements in science and technology depend on scientific knowledge, skills and attitudes to be adopted as a way of life. Despite the importance of general science, in particular physics, the related literature shows that the students at all the grades from elementary school to tertiary level have difficulty in learning science and physics, develop negative attitudes towards science and it affects adversely their career choices related to science $[1,2]$.

Studies conducted in science education have shown that students have difficulty in learning physics topics such as light, sound, optics, electricity, and magnetism, and there are many conceptual misunderstandings on these issues. Optics and light are the topics that students encounter very often in their daily lives. However, the related research has shown that he students at all levels from elementary school to university level have many problems in optics and light topics such as image formation, reflection, refraction, concave and convex lenses and the conceptual understanding level of students is also low. Besides, it was expressed that the role of the observer is ignored during the observation of image formation in the textbooks; students have misconceptions about the correlation between the position of the observer and image, the location of the image on a plane mirror, the correlation between the image and object, and the characteristics of the image [3-10]. Another important issue of physics is electricity and magnetism. Research has shown that students have a lot more difficulty in magnetism despite they encounter with the examples of magnetism issues more than those of the electricity in daily life. It is stated that using complex mathematical operations for determination of magnetic quantities and teaching subjects notionally through 
verbal symbols make it difficult for students to learn these issues. Furthermore, it is found out in the related studies that students have misconceptions about the issues of the changes of brightness of the lamps with the change of resistance, current, series and the parallel connection of resistance, ohm's law and circuit theory [11-16].

This and other similar learning difficulties revealed in the previous studies may occur based on various factors such as learning environments, teacher qualifications, textbooks and like. Science education researchers suggest designing new learning materials and an active learning environment in order to overcome these learning difficulties. Yet, the research shows that traditional science teaching practices are not effective in developing students' high level cognitive skills. The construction of knowledge and effective learning require a student-centered learning environment so that students can actively participate in the experiential learning activities $[5,14,17]$. Across the world, science teaching research continually focuses on learning conditions, teaching methods and techniques which will provide us with the best learning outcomes in science education. Researchers have a consensus on that traditional teaching methods, which make the teacher active and the students passive in the process of teaching, fail to enable students with the desired achievement levels [18]. The research conducted especially in the field of physics teaching has shown that it is quite difficult to learn physics with traditional education methods. Therefore, it was stated there is a need to employ methods which make the students participate actively in the process by investigating, questioning and learning by doing [2, 19-21].

The laboratory method is considered one of the leading teaching methods to realize effective and meaningful learning in science education which is the basis of scientific and technological developments. The laboratory method, which is based on the students' active participation in the process of the analysis of the actual events and data collection, provides opportunities for students to understand the core and method of science, to develop problem-solving abilities, to investigate and make generalizations, to gain scientific knowledge and to develop positive attitudes [22-24]. An important part of science education is to test the theories and hypotheses in laboratory practices. Teacher training programs involve theoretical physics, chemistry and biology courses, laboratory courses including experimental applications of the topics in these lessons and methodology courses including teaching of science topics in the laboratory. In these courses, while the prospective teachers are aimed to learn the theoretical and application aspects of science subjects, they are also taught how to teach these subjects. Although laboratories are an important part of science education, research has revealed that all lab activities do not provide significant contributions for teaching-learning process. The main reason for this is regarded the use of traditional confirmatory activities in laboratories. Since the students attending traditional confirmatory laboratory activities carry out an experiment by following the instructions given to them step by step, they do not fully understand the test process. Consequently, traditional laboratories usually become ineffective in teaching science concepts. For this reason, the necessity of implementing new approaches in laboratory practices as well as in theoretical courses has been the focus of attention for researchers $[1,2$, 19, 21, 25-29].

Adeoye [19] stated that cooperative learning is one of the most appropriate methods for physics teaching. It is emphasized that the methodology courses in teacher training programs are needed to be organized in a way that will allow the integration of cooperative learning into teaching. It is indicated that in order to achieve the objectives of physics education, the methods including problem detection, problem solving, decision making, experiential learning and discovery learning should be centered in physics teaching strategies. In the studies of Tanel and Erol [20], a jigsaw technique was used during theoretical and laboratory teaching of magnetism. While a traditional narration method was used for teaching theoretical subjects in the control group and deductive method was employed for laboratory practices in the experimental group. The results of the study show that cooperative learning in teaching magnetism is more effective than traditional methods in terms of increasing academic achievements and ensuring the retention of knowledge at tertiary level. At this point, it will be important to determine which laboratory approach will be effective on developing student behaviors in cognitive, affective and psychomotor domains. The current study investigates the use of cooperative learning, one of the active learning methods in science teaching, in laboratory practices.

Cooperative learning is a teaching model that helps students to learn from each other in small heterogeneous groups in terms of various variables. Cooperative learning model has application practices in different cultures, different geographies and at all educational levels from elementary school to university and in many areas [30-33]. In general, cooperative learning is considered to have positive effects on the academic achievement of learners, the development of social skills, the personality traits and psychological variables. In addition, it is stated that there are important contributions of cooperative learning to the development of personal and professional skills. Research has mostly focused on which applications of cooperative learning are effective on variables and to what extent, and in which circumstances these effects are valid. Thus, different in-class applications of cooperative learning have emerged. Today there are different cooperative learning methods and techniques which are applied at various levels of education all over the world and in different subject areas. The studies still seek for the ways to enhance the effects of these methods and to develop more effective in-class practices [31, 34-36]. Jigsaw, one of the techniques which is used in the implementation of cooperative learning, brings the cooperation to the forefront by providing support to students' working together and removing competition in the classroom. 
The technique of jigsaw based on cooperative learning is also seen as an alternative to traditional teaching methods in terms of this aspect [32].

The technique of jigsaw based on cooperative learning is a kind of technique which has applications in different areas of science, language teaching, foreign language teaching, social sciences and medical science and has emerging examples of different in-class practices based on the developments in the course of time. The properties of the domain and the subject area have undergone various modifications in terms of the duration of the group work (a unit or a single topic), teaching materials used, activities, assessment processes, the organization of the groups, the approaches of creating dependency, giving responsibility, providing motivation approaches, and reward structures. This variability has revealed different types of the original Jigsaw. In the literature, there are six different jigsaw techniques along with the original Jigsaw, Jigsaw II-III-IV, reverse Jigsaw and subject Jigsaw [37-43]. Some of the reasons for Jigsaw technique to be prominent for educators are searching for many answers in one question for the group work conducted through this technique, equal opportunities in learning and allowing communication between students with different learning histories. However, in other techniques, it is stated that only one correct answer is usually searched for one question, that is, a group is in a struggle to arrive at a single correct answer [38, 41, 43, 44].

Individuals need to cooperate with others in order to accomplish the learning tasks which are based on no predetermined answers and solutions. In this way, cooperative learning becomes meaningful (logical) for individuals. Students show different learning efforts and social behaviors while searching for possible solutions to the questions, and collecting information. In this process, students change their ideas on the topic, expand their understanding of the subject matter and discuss how to combine the data they compiled and their plans to perform a task. It is recommended that working with a Jigsaw technique is one of the best ways to actualize this learning and social behaviors [45]. Each team member is responsible for a part of the subject in the Jigsaw method based on cooperative learning applications, and this is the main difference between the jigsaw and other cooperative learning methods. Thus, everyone has to take part in the activities within the group. As a result of this active participation, each group member is enabled to learn the concepts in focus [31, $37,41,46]$.

The studies revealed that teaching science topics, especially physics, needs to be implemented in learning circumstances in which students can reflect their ideas and discuss their learning with their friends and teachers instead of well-planned lecturing methods [1, 20, 47, 48]. Since cooperative learning is not widely used to facilitate interaction and students' learning in an educational environment by teachers, teacher education plays an important role at this point. A teacher who has no experience with cooperative learning is not expected to apply this method in his/her class. Research emphasizes that in order to support teachers to implement cooperative learning in their classes, teachers in-service need to be provided with training for their continuing professional development, and learning environments need to be created for prospective teachers to develop their cooperative learning experiences [19, 48, 49]. In this regard, it is considered important for teaching physics to use Jigsaw technique based on cooperative learning which makes students help each other's learning in small mixed groups and provides learning opportunities for searching, discussing and investigating. In addition, Jigsaw technique can easily be used for both teaching theoretical subjects and carrying out laboratory experiments in terms of its structure in the implementation process. However, this study is regarded important in terms of providing cooperative learning experiences for the participating tertiary level students attending a science teaching program.

\subsection{Research Goal and Questions}

The main objective of this research is to determine the influence of a Jigsaw based on cooperative learning method and a confirmatory laboratory method on prospective science teachers' achievements of physics in science teaching laboratory practice lesson. The following sub-problems of the current research seek for answers.

1. Does teaching physics in science teaching laboratory practice course with a Jigsaw method based on cooperative learning and a confirmatory laboratory method make differences between the achievements of groups?

2. What are the misconceptions of the student groups getting training with a Jigsaw method based on cooperative learning and a confirmatory laboratory method regarding physics in science teaching laboratory practice course?

\section{Methods}

The present research was carried out by using a quasi-experimental post-test-only control group design. In the research, science teaching laboratory practice course was conducted in accordance with a Jigsaw method based on cooperative learning in the experimental group and the confirmatory laboratory method in control group. Following the treatment, Science Laboratory Physic Achievement Test (SLPAT) was administered as a post-test.

\subsection{Sample}

The sampling of this study consisted of 33 female and 15 male third-grade prospective science teachers (6th term) who attended science teaching laboratory practice course in the 2014-2015 academic year. The mean for ages of the participating students was computed as 21.38. The group having practices through Jigsaw method was named as Cooperative Learning Group (JCLG) $(n=23)$, and the other 
group using the confirmatory method was called as the control group (CG). The participating student teachers attended the courses of basic and advanced physics, chemistry, and biology in the first five semesters, and most of them have completed these courses successfully. The student teachers were evaluated according to their prior knowledge levels and the Grade Point Average (GPA). The data related to overall GPA were obtained from the lists of every class which were taken from the student administration office. GPA is calculated by the following process: beginning from the first semester a student started the program and including the semester which has been just completed, the credit hour of each lesson enrolled is multiplied with a predetermined coefficient unit $(0,00-4,00)$ of these lesson's grade. Then, all these are summed up and the summary is divided into total credit hours, and finally divided and rounded upward to 2 decimal places.

\subsection{Instruments}

In order to determine the prospective science teachers' understanding of physics topics in a science teaching laboratory practice course, the Science Laboratory Physics Achievement Test (SLPAT) was prepared by the researcher. The SLPAT included basic topics of sound, light, heat and temperature, electricity and magnetism in the scope of the laboratory practices. Theoretical and practical aspects of the lesson were taken into consideration while preparing the questions relevant to these issues. The specified sub-topics have been chosen taking into account the experiments carried out. SLPAT was formed in ten (10) open-ended questions in order to determine students' understanding regarding sound characteristics, image formation and image characteristics in mirrors and lenses, simple electric circuits, circuit elements and their tasks in electric circuit, the impact of the heat on materials, magnetic fields, magnetic objects, magnetization and magnetization features. Learning objectives of the questions in the SLPAT are as follows: (1) to determine the relation between the length of a metal strip used as the sound source and the intensity of the sound that occurs, (2) to design the experimental setup that shows the relation between the voice amplitude and its intensity, (3) to explain the reasons of the ways of connecting ampermeter and voltmeter to a simple electric circuit, (4) to explain the reasons of series and parallel connections of identical batteries used as the generator in an electric circuit, (5) to compare the brightness (intensity of light) of the identical lamps connected in series and parallel in an electric circuit, (6) to write the properties of an object's image on a plane mirror and to explain the reasons of an image being virtual, (7) to draw the actual image of an object in the concave mirror and the convex lens (two questions), (8) to write the types of magnetization, and to determine the poles of the temporary magnet that are formed through friction and magnetization, and (9) to write and define the expansion types and expansion coefficient. Moreover, two experts in the field of physics teaching and science teaching were consulted in order to ensure the construct validity of the SLPAT. The experts were given a form that included the questions and the learning objective intended to be measured by each question, and they were asked to evaluate whether the questions in the test measure the intended meaning. Based on the necessary analysis, it was concluded that the experts achieved a consensus on the questions' appropriateness for the intended learning objectives. The questions in SLPAT involved the tasks of writing properties in steps, making statements, designing the experimental setup and drawing. Questions for all the basic issues were included, but more questions were involved on some issues considering the sub-topics in SLPAT. Thus, the content validity of SLPAT was tried to be ensured. The prepared questions were evaluated by two experts on the field of physics education and science education and two science teachers, and the test was finalized. The answers of student teachers in the research groups for the SLPAT were scored according to the prepared analytical answer key. By making independently partial scoring for all questions, the score is given for each question among 0-10. Cronbach Alpha reliability coefficient was calculated for SLPAT as 0.66. The maximum score students can take from SLPAT is 100 points. In addition, misunderstandings that were detected in the answers given to the questions in the SLPAT by student teachers were identified, and frequency values of these misunderstandings were calculated. Thus, it was aimed to evaluate both conceptual understandings and the success of the research groups.

\subsection{Procedure}

This research was carried out in accordance with a quasi-experimental post-test-only control group design. In this section, experimental applications carried out during the treatment are presented. The Science Teaching Laboratory Practice (STLP) course was conducted through a Jigsaw method based on cooperative learning in the Jigsaw Cooperative Learning Group (JCLG) and a confirmatory laboratory method in the control group (CG). In the treatment process, the same experiments performed in both research groups were selected from the same source books. In addition, the topics discussed in the theoretical lessons were the same for both groups. In both groups, along with two assistants, the researcher participated in the laboratory practice. Theoretical lessons were conducted by the researcher.

\subsubsection{Teaching through Jigsaw Method Based on Cooperative Learning}

The students in the JCLG were divided into five heterogeneous "Jigsaw Groups" consisting of five members since physics topics in the STLP course is divided into five subtopics. Jigsaw Groups were encoded with a "JG" icon and letters according to the alphabet and shown in figure 1. While composing the groups, students in JCLG were ranked according to their GPA. It was considered that each group 
was heterogeneous in itself and homogeneous among themselves in terms of achievement. The groups were given forms including the personal information of the group members, member codes and a color to represent the group. In addition, these forms included the contents of the topics that would be taught during the course and numbers of the experiments in the textbooks which would be conducted in the course. Students in the JGs were given information about their duties and responsibilities in the lesson, the activities they would carry out and the implementation of the Jigsaw technique. Then, the JGs were asked to bring information about the topics in the course content until the next lesson. In the next lesson, they came together in their JGs, and each member of the group was assigned a subtopic of the course content to learn it as an 'expert'. The JGs then broke apart, and the student teachers assigned the same topics moved into the Expert Groups consisting of members from each $\mathrm{JG}$.
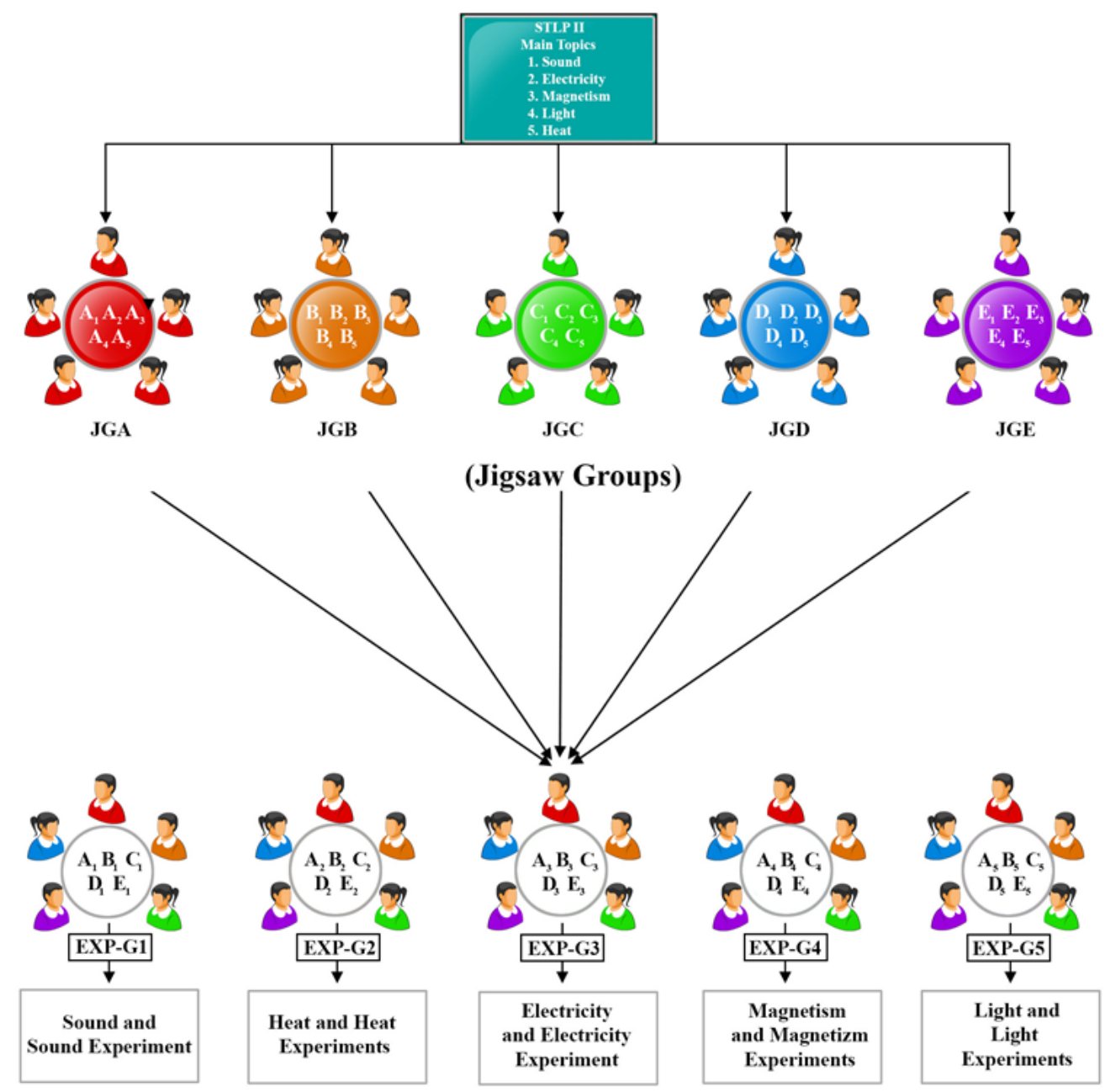

(Expert Groups)

Figure 1. The work order formed for jigsaw method 
Expert Groups were composed by gathering the student teachers taking the same subtopics together. Five Expert Groups consisting of 5 members were formed. The expert groups represented by the symbol "EXPG" and a code number were shown in figure 1. The EXPGs were given the tasks of searching for their subtopics in a detailed way, learning the subtopic and teaching their area of expertise to other friends when they returned to their JGs which were composed at the beginning of the course. The EXPGs conducted their research and learning activities in and out of the class. Four class hours were allocated for these activities, and other studies were performed outside the class. The work of the EXPG was followed by the teacher during the lessons, they were given support when necessary, and they were guided. In this way, students were enabled to be experts of their subtopics. After the theoretical part of the EXPG work was completed, each EXPG carried out the experiments in the textbooks which were selected for the lessons related to their topics of expertise. Experiments were completed within a period of two hours. All the EXPGs prepared their own reports including both theoretical information related to the issues of expertise and the implementation processes of the experiments which were carried out, and each member of the group took a sample of this report. After completing the studies in the EXPG, each student returned to their own JG. Thus, it was ensured that each group member got specialized in both the theoretical and implementation aspects.

Each member of the JGs taught the subtopics in their areas of expertise to other group members through activities carried out in an out of the class. Furthermore, they shared the application process of their experiments which were carried out in the EXPGs with the group members. Thus, group members learnt theoretical information about the topics in the scope of the course and got ready for the experiments which were carried out by making similar studies in all JG. Later, JGs performed the experiments related to the five main topics of the course in turns in two-hour periods. JGs prepared their reports of the experiments in all the subtopics using data from the experiments and observations findings. The implementations, which were performed by Jigsaw method based on cooperative learning, were completed in 5 weeks (20 lessons). In all the lessons of the course, it was allocated a two-hour period on the work in the first JGs, a 4-hour period on the EXPGs, a 4-hour period on the work in the second JGs and a 10-hour period on the experimental applications.

Table 1. Breakdown of the expert group for STLP course content

\begin{tabular}{|c|c|c|}
\hline $\begin{array}{l}\text { Expert Groups and } \\
\text { Main Topics }\end{array}$ & Sub-Topics & Experiments \\
\hline $\begin{array}{l}\text { EXP-G1 } \\
\text { Sound }\end{array}$ & $\begin{array}{l}\text { Formation of Sound } \\
\text { Characteristics of Sound } \\
\text { Spread of Sound }\end{array}$ & $\begin{array}{c}\text { Sound formation from vibrated ruler } \\
\text { Obtain various sounds from the test tubes } \\
\text { The intensity of the sound (in the tuning fork) } \\
\text { Resonance } \\
\text { Xylophone }\end{array}$ \\
\hline $\begin{array}{c}\text { EXP-G2 } \\
\text { Light }\end{array}$ & $\begin{array}{c}\text { Basic Concepts about Light } \\
\text { Light Sources } \\
\text { Spread of Light } \\
\text { Transparent and Non-transparent } \\
\text { Materials } \\
\text { Seeing Event } \\
\text { Reflection of Light } \\
\text { Refraction of Light }\end{array}$ & $\begin{array}{l}\text { Transparent and non-transparent materials } \\
\text { How does the Shadow occur? } \\
\text { How does the image occur? } \\
\text { Image formation in plane mirrors } \\
\text { Image formation of pits and convex mirror } \\
\text { Image formation of concave and convex lens }\end{array}$ \\
\hline $\begin{array}{c}\text { EXP-G3 } \\
\text { Heat }\end{array}$ & $\begin{array}{l}\text { Basic concepts } \\
\text { Heat conduction } \\
\text { State Changing } \\
\text { Heat Spreading } \\
\text { Expansion } \\
\end{array}$ & $\begin{array}{l}\text { Do different solids transmit the heat at the same speed? } \\
\text { Examination of heated water movement } \\
\text { The heated air rises } \\
\text { Why does not the heated coin pass through between metal nails? } \\
\text { Examination of volume expansion }\end{array}$ \\
\hline $\begin{array}{l}\text { EXP-G4 } \\
\text { Electricity }\end{array}$ & $\begin{array}{c}\text { Basic Concepts } \\
\text { Simple Electric Circuit } \\
\text { Serial, Parallel and Mixed Circuits } \\
\text { Electrical Conductivity of Different } \\
\text { Materials } \\
\text { Factors Affecting the Conductivity }\end{array}$ & $\begin{array}{l}\text { The ammeter connecting to the circuit and measuring the current } \\
\text { The voltmeter connecting to the circuit and measuring the potential } \\
\text { difference } \\
\text { Investigation of light intensity by connecting lamps in series and parallel } \\
\text { What does the resistance of a conductor depend on? } \\
\text { Serial and parallel connection of batteries } \\
\text { Comparison of the electrical conductivity of the fluid }\end{array}$ \\
\hline $\begin{array}{l}\text { EXP-G5 } \\
\text { Magnetism }\end{array}$ & $\begin{array}{c}\text { Magnetic Field and Magnetism } \\
\text { Magnetic Field of Wire Through Passing } \\
\text { Current } \\
\text { Magnetism Property and Magnetic Poles }\end{array}$ & $\begin{array}{c}\text { Occurring Magnetic field around the wire through passing current } \\
\text { How does eddy current occur? } \\
\text { Electromagnets } \\
\text { Examination of the magnetic field of a magnet } \\
\text { Magnetization by influence and friction }\end{array}$ \\
\hline
\end{tabular}




\subsubsection{Teaching through Confirmatory Laboratory Method}

In the CG where confirmatory laboratory method was applied, STLP course was conducted in two stages. In the first stage, the presentation of theoretical course content was performed while in the second stage, or the application stage, the experiments were conducted. In the first phase of the lesson, the topics were presented by the teacher using the lecturing method according to the pre-prepared lecture notes. During the presentation, examples were given, students were asked to give examples, questions were asked and answers were taken from students. In the teaching process, formulas related to the subject, the digital process and drawings were transferred to the student teachers on the blackboard. The students asked questions to the teacher regarding the subjects and concepts which they did not understand or they were curious in the teaching process, and the teacher informed the students by answering the questions, going over the topics, and through different viewpoints. The lecturing was completed in a ten-hour period. After completing the lecturing, page numbers of the experiments in the practice textbook were given to students, and the teacher asked them to get prepared for the experiments which would be carried out every week. The tools that were used in the experiments related to five key issues (see Table 1) including course content were placed on five separate experiment tables. In order to carry out the experiments, five groups were composed in the control group $(\mathrm{N}=23)$, in which two of them consisted of 4 members and three of them involved 5 members. Group members worked together until all the experiments were completed. All the groups completed the experiments on each table in a two-hour period. Each group carried out an experiment on a different table at the same time. In the next lesson, experiment tables were changed in accordance with a sequence of the subject, and all the experiments on five tables were carried out. After completing the experiments, groups prepared individual reports related to this experiment until the next lesson. Received reports were compiled in the student files for evaluation.

\subsection{Analysis of the Data}

Descriptive statistics belonging to the grade point average (GPA) of the student teachers in research groups which were obtained from the student affairs were calculated, and independent groups were analyzed via t-test. In addition, descriptive statistics were also calculated for the scores students received from the Science Laboratory Physics Achievement Test (SLPAT), and analysis of covariance (ANCOVA) was performed for the SLPAT points based on GPA as a covariate. Furthermore, frequency values of common wrong answers of the students to questions in SLPAT were calculated.

\section{Results}

The findings of the data gathered through the data collection tool used in the study are presented in two categories. The prospective science teachers' achievement levels of physics topics in the science teaching laboratory practice course were evaluated according to the scores obtained from the SLPAT. For the SLPAT, the students' written responses were analyzed, and their conceptual misunderstandings of physics topics were determined.

\subsection{Findings Regarding the Achievements of the Students in Research Groups on the Physics Topics}

Descriptive statistics regarding the GPA and SLPAT scores of the students in the research groups were calculated, and shown in Table 2.

Table 2. Descriptive statistics regarding the GPA and SLPAT scores

\begin{tabular}{|c|c|c|c|c|}
\hline Variable & Group & $\mathrm{N}$ & Mean & $\begin{array}{c}\text { Std. } \\
\text { Deviation }\end{array}$ \\
\hline GPA & JCLG & 25 & 2.13 & .577 \\
\hline & CG & 23 & 1.83 & .544 \\
\hline SLPAT & JCLG & 25 & 61.08 & 13.613 \\
\hline & CG & 23 & 51.87 & 9.577 \\
\hline
\end{tabular}

According to Table 2, it is clear that the student teachers in the JCLG have higher SLPAT average scores and GPA than those of the CG. Independent samples t-test was performed to determine whether there is a difference among GPA statistics of the research groups. Analysis results showed no statistically significant difference between the GPA of JCLG and CG ( $\mathrm{t}=1.861 ; \mathrm{p}=0.069)$. In this study, GPA was taken as an indicator of the students' prior knowledge levels. The correlation between the GPA and SLPAT scores of students who participated in the research was examined considering the effect on subsequent learning. The results of the Pearson correlation analysis showed a high level significant positive correlation between the SLPAT scores and the GPA of the students $(r=0.774$; $\mathrm{p}<0.01 ; \mathrm{N}=48$ ).

To investigate the effects of the jigsaw method based on cooperative learning and the confirmatory laboratory method on students' achievements in terms of physics topics, analysis of covariance (ANCOVA) for the SLPAT scores was conducted by taking the GPA scores as the covariates, and the analysis results are shown in Table 3. 
Table 3. ANCOVA results for the SLPAT scores

\begin{tabular}{|c|c|c|c|c|c|c|}
\hline Source & Type III Sum of Squares & $\mathrm{df}$ & Mean Square & $\mathrm{F}$ & $\mathrm{p}$ & $\begin{array}{c}\text { Partial Eta } \\
\text { Squared }\end{array}$ \\
\hline Corrected Model & $1027.434^{\mathrm{a}}$ & 2 & 513.717 & 3.582 & .036 & .137 \\
\hline Intercept & 10300.436 & 1 & 10300.436 & 71.822 & .000 & .615 \\
\hline EcAT pretest & 11.216 & 1 & 11.216 & .078 & .781 & .002 \\
\hline Groups & 891.325 & 1 & 891.325 & 6.215 & .016 & .121 \\
\hline Error & 6453.733 & 45 & 143.416 & & & \\
\hline Total & 161614.500 & 48 & & & & \\
\hline Corrected Total & 7481.167 & 47 & & & & \\
\hline
\end{tabular}

Table 4. Conceptual misunderstandings of the students in the research groups about sound topic

\begin{tabular}{|c|c|c|}
\hline Statements of the students & CG (f) & JCLG (f) \\
\hline If stress increases, amount of the wavelength increases, so intensity of the sound increases as well. & \multirow{7}{*}{10} & \multirow{7}{*}{9} \\
\hline Since the number of vibrations is a lot, violence of the sound is a lot as well. & & \\
\hline If stress increases the amount, frequency increases and intensity of the sound increases accordingly. & & \\
\hline When the amount of stress increases, sound thickens. & & \\
\hline When the amount of stress increases, molecules move more freely up and vibrates more severely. & & \\
\hline If stress increases, frequency increases and sound gets shrill; however, the sound intensity decreases. & & \\
\hline $\begin{array}{l}\text { When stress increases, the wavelength of sound increases and intensity of the sound decreases } \\
\text { accordingly. }\end{array}$ & & \\
\hline
\end{tabular}

Table 5. Wrong answers for the reasons of connecting a voltmeter to circuit in parallel

\begin{tabular}{|c|c|c|}
\hline Statements made by students & $\mathrm{CG}(\mathrm{f})$ & JCLG (f) \\
\hline $\begin{array}{l}\text { If it was connected in parallel, total potential would be wrong because it measures the } \mathrm{p} \\
\text { single source. }\end{array}$ & \multirow{4}{*}{9} & \multirow{4}{*}{7} \\
\hline If it was connected in a series, it would cause a short circuit. & & \\
\hline It is connected in parallel because of the shape of the circuit mechanism. & & \\
\hline It is connected in parallel for measuring the potential of all circuits. & & \\
\hline
\end{tabular}

The results of the analysis in Table 3 showed a significant difference among the SLPAT corrected average scores of the students in JCLG and CG $(\mathrm{F}(1,45)=6.215$; $p=0.016 ; p<0.05)$. When SLPAT adjusted average scores of the research group were examined, it is seen that the detected differences were in the favor of the experimental group (XJCLG $=60.953 ; \mathrm{XCG}=52.008)$. That is to say, teaching physics topics in "The Science Teaching Laboratory Practice" course via the Jigsaw method based on cooperative learning has revealed a higher level of achievement than teaching through the confirmatory laboratory method.

\subsection{Findings Related to the Students' Conceptual Misunderstandings of Physics Topics}

Table 4 presents the expressions of conceptual misunderstandings of the student teachers gathered through the question of how the intensity of a sound changes when increasing the distance of a metal strip, which is stuck to a fixed support, from a surface without changing its length.

When the statements are examined in Table 4, it was found that students who participated in the research (CG \%43, JCLG \%36) had misunderstandings about the sound subject in the way that there is a positive or negative correlation between the intensity of sound and wavelength, and when amplitude increases, frequency increases and the intensity of sound increases accordingly. It was also seen that the students had conceptual misunderstandings in the way that sound intensity and loudness are (high-pitched, low-pitched sound) the same property, and when the amplitude increases, the molecules compose a more severe tone by moving more freely.

In another question, the student teachers were asked to explain the reasons of the connection of an ammeter and a voltmeter to a circuit. It was seen that students mostly had difficulty in explaining the reasons for connecting a voltmeter to a circuit in parallel. Frequently encountered answers of the students in research groups related to the reason of connecting a voltmeter to a circuit in parallel are given in Table 5.

When the responses in Table 5 were examined, it was understood that students had misunderstandings in the way 
that a voltmeter is connected to a circuit in parallel for measuring the total potential of a circuit, and if a voltmeter is connected to a circuit in series, it would cause a short circuit. Students also stated that a voltmeter should connect to a circuit in parallel in order to complete only a simple electric circuit as formally.

The wrong answers mostly given by the students in the research groups related to the reasons of connecting the identical batteries used in a circuit as the generator to a circuit in parallel and series are given in Table 6.

Table 6. The wrong answers of the reasons related to connecting batteries to a circuit in parallel and series

\begin{tabular}{|c|c|c|c|}
\hline Way of Connection & Statements made by students & CG (f) & $\operatorname{JCLG}(\mathrm{f})$ \\
\hline \multirow{5}{*}{$\begin{array}{l}\text { The reasons of connecting } \\
\text { the batteries in series }\end{array}$} & $\begin{array}{l}\text { When batteries are connected in a series, the current passing in all ways will be the } \\
\text { same. }\end{array}$ & \multirow{5}{*}{11} & \multirow{5}{*}{10} \\
\hline & Batteries are connected in parallel using the energy of only one. & & \\
\hline & Batteries are connected in a series in order that a current can pass in one branch. & & \\
\hline & Because connecting to a circuit in series is a suitable connecting series. & & \\
\hline & When it is connected series, the total stress is equal to the stress of one battery. & & \\
\hline \multirow{6}{*}{$\begin{array}{l}\text { The reasons of connecting } \\
\text { the batteries in parallel }\end{array}$} & $\begin{array}{l}\text { When batteries are connecting in parallel, the currents passing in all branches are } \\
\text { different. The current is divided into branches. }\end{array}$ & \multirow{6}{*}{12} & \multirow{6}{*}{8} \\
\hline & In order to use the energy of only one battery, the batteries are connected parallel. & & \\
\hline & $\begin{array}{l}\text { Providing the current in a circuit divided into branches the batteries are connected } \\
\text { parallel. }\end{array}$ & & \\
\hline & Because connecting to a circuit in parallel is a suitable connecting parallel. & & \\
\hline & When we connect in parallel we can pass the power wherever we want. & & \\
\hline & In order to give more current to the circuit, the batteries are connected parallel. & & \\
\hline
\end{tabular}

Table 7. The misconceptions concerning how brightness of the lamps will change according to connection way of identical lamps

\begin{tabular}{|c|c|}
\hline \multicolumn{1}{|c|}{ Statements made by students } & JCLG (f) \\
\hline $\begin{array}{r}\text { As current passes through one way (same current will pass) with a connection in a series, the light intensity of the } \\
\text { lamps are the same. It would be different in the parallel connection, it varies. }\end{array}$ & $\begin{array}{c}\text { the ratio of } 1 / 3 . \\
\text { If series connected lamps are connected in parallel, the potential difference between the ends of each lamp reduces in } \\
\text { brightness of the series connected lamps is more. }\end{array}$ \\
\hline $\begin{array}{c}\text { The light intensity of the lamps connected in parallel is less than a series, but they are equal to each other. But the } \\
\text { in three branches. }\end{array}$ \\
\hline $\begin{array}{c}\text { If the lamps connected in a series are connected in parallel, the equivalent resistance decreases, the current increases, } \\
\text { but light intensity of lamps decreases as the current is divided into branches. }\end{array}$ \\
\hline $\begin{array}{c}\text { As Current is divided into branches through the parallel circuit, the same current flows through each lamp and their } \\
\text { brightness is the same. The light intensity of the lamps connected in a series is different. Because the current is } \\
\text { gradually reduced. }\end{array}$ \\
\hline
\end{tabular}

Table 8. The wrong answers about the causes of the image to be virtual in plane mirror

\begin{tabular}{|r|r|}
\hline Statements made by students & JCLG (f) \\
\hline $\begin{array}{r}\text { The image is virtual because it is a reflection of the body. } \\
\text { The image is virtual because after they are reflected in the mirror, incoming light rays create a virtual image by } \\
\text { The image is virtual because the light rays cut each other. }\end{array}$ & 16 \\
\hline The image is virtual because it does not fall on any curtain-screen. & The image is virtual because the image is behind the mirror. \\
\hline The image is virtual because the angles of incoming light rays are equal with their angles of the reflections. & The image is virtual because the image is the same with the body. \\
\hline The image is virtual because an exactly clear image doesn't occur. & \\
\hline The image is virtual because light rays coming on a plane mirror reflect with the same angle. & \\
\hline Image of a plane mirror is virtual because it is symmetrical with the object. & \\
\hline
\end{tabular}


The statements in Table 6 indicated that the student teachers who participated in the research had misunderstandings in the way that for utilizing power of all batteries, they should be connected in series, and for utilizing the power of only one battery, they should be connected in parallel. In addition, it was found out that the students had misconceptions in the way that when batteries are connected to a circuit in series, current passes in one branch, and while it is connected in parallel, the current would be divided into branches. However, some student teachers stated their opinions on this issue without explaining any reasons. At the same time, contrary to the fact scientifically accepted by al, students gave the answers that batteries should be connected to a circuit in parallel for obtaining a high voltage or providing a high current.

Table 7 presents the most common misconceptions of the students in the research group for the question of how the brightness of the lamps changes when identical lamps in a series are converted into parallel without replacing the generators.

Statements in Table 7 show that students had misunderstandings in the way that when the identical lamps connected in a series were converted to the parallel connection, potential difference between the ends of each lamp reduces in the ratio of the number of lamps, or the current in a circuit is divided into branches as much as the number of lamps, and the current in the circuit will not change and so the brightness of the lamps will reduce. In addition, it was seen that students had misunderstandings in the way that if the identical lamps connected in a series are converted to parallel connection, the brightness of the lamps will not change. Besides, it was seen that students had correct information about if the identical lamps connected in a series are converted to parallel connection, the equivalent resistance will reduce. However, it was found out that there were misunderstandings in the issue that the current for each lamp will decrease by disregarding the fact that the current in the circuit will increase and the potential difference between the ends of each lamp is equal to the potential difference of the generator, and thus the brightness of the lamps will decrease.

In another question, the student teachers were asked to write the properties of an object image formed in a plane mirror and to explain the causes of the image to be virtual. When the written answers to the question were examined, it was seen that students gave the wrong answers about the causes of the image to be virtual in a plane mirror. Frequently encountered wrong answers of students in the research group are presented in Table 8 .

Given the data in Table 8, it was seen that contrary to scientific facts, the student teachers answered the question about the causes of the image to be virtual in a plane mirror in the way that after the incoming light rays are reflected in the plane mirror, they create a virtual image by intersecting in front of the mirror. It was also seen that some of the student teachers had correct information about the issues that the image cannot fall on any screen because the image of a plane mirror is virtual, the image is inside the mirror, and the image and the object are simultaneously symmetrical to each other. Yet, these situations are the result of a virtual image. Student teachers who indicated these explanations as the reasons for the image to be virtual had conceptual misunderstandings. Students tried to explain the virtual image with the features of the image.

Table 9. The wrong answers regarding the examination of the actual image on the concave mirror

\begin{tabular}{|c|c|c|c|}
\hline & Description of the drawings by students & $\mathrm{CG}(\mathrm{f})$ & JCLG (f) \\
\hline \multirow{4}{*}{$\begin{array}{l}\text { The location of the } \\
\text { object and the image }\end{array}$} & The object is outside the center, the image is behind the mirror between $\mathrm{F}$ and $2 \mathrm{~F}$. & \multirow{4}{*}{7} & \multirow{4}{*}{9} \\
\hline & The object is in front of the mirror, (the position is undefined) the image is behind the mirror. & & \\
\hline & The object is in focus, the image is behind the mirror at infinity. & & \\
\hline & The object is at the center, the image is behind the mirror at the center. & & \\
\hline Screen Display & The screen was not used to observe the image. & 9 & 12 \\
\hline \multirow{2}{*}{$\begin{array}{c}\text { The location of the } \\
\text { observer }\end{array}$} & The observer is behind the objects and looking toward the object-mirror line. & \multirow{2}{*}{12} & \multirow{2}{*}{11} \\
\hline & The observer is looking on the side where the mirror is not located (behind the mirror). & & \\
\hline
\end{tabular}

Table 10. The wrong answers regarding the examination of the actual image on the convex lenses

\begin{tabular}{|c|c|c|c|}
\hline & Description of the drawings by students & CG (f) & JCLG (f) \\
\hline \multirow{3}{*}{$\begin{array}{c}\text { The location of the } \\
\text { object and the } \\
\text { image }\end{array}$} & The location was not specified, the image is in the lens. & \multirow{3}{*}{7} & \multirow{3}{*}{8} \\
\hline & The object is in focus, the image is in the other side between the lens and focus. & & \\
\hline & The location was not specified, the image is on the side where the object was located. & & \\
\hline Screen Display & The screen was not used to observe the image. & 8 & 10 \\
\hline \multirow{2}{*}{$\begin{array}{l}\text { The location of the } \\
\text { observer }\end{array}$} & The observer is looking toward the lens on the side where the object was located. & \multirow[b]{2}{*}{5} & \multirow[b]{2}{*}{7} \\
\hline & $\begin{array}{l}\text { The observer is looking toward the direction of lens-object on the other side where the } \\
\text { object was not located. }\end{array}$ & & \\
\hline
\end{tabular}


In the two different questions of the data collection tool used for the research, the students were asked to draw the experimental setups which examined the real image of the body in the concave mirror and convex lens without showing the rays but covering the position of the observer. The responses of the student teachers were elaborately examined in terms of the representation of a concave mirror and a convex lens, the location of the body and the image, the usage of a screen for showing the real image and the location of the observer. Frequently encountered misunderstandings by the students are shown in Table 9 and Table 10 by converting them to written statements.

According to Table 9, it can be seen that the student teachers had conceptual misunderstandings in the way that the real image of an object on the concave mirror occurs behind the mirror. Furthermore, not using a curtain or screen for examining the real image emerged as a significant factor. However, in the experimental setups, the representation of the observer who examined the real image and located on the side of the mirror where the object did not exist, indicated the misunderstandings of the students.

Given the data in Table 10, it can be seen that students had conceptual misunderstandings in the way that the real image of an object on the convex lens occurs in front of the mirror, in other words, on the side where the object is located. Furthermore, not using the curtain or screen for examining the real image emerged as a significant factor. However, in the experimental setup, the representation of the observer who examined the real image and located on the back of the lens where the object was not located, indicated a significant misunderstanding of the student teachers. At this point, they thought that the real image of the convex lens was formed on the side where the object was located.

In the question about the magnetization in the SLPAT, the student teachers were asked to write the magnetization types step by step and to figure out the pole of the temporary magnet which is obtained by rubbing the magnet constantly in an iron of the same direction as in Figure 2. In their responses to this question, it was found that students often had difficulty in understanding the temporary magnet poles which were formed by frictional magnetization, and drawing samples of this misunderstanding are presented in Figure 2.

The descriptions of the student teachers in the Figure 2: "They attract each other because of the different poles (Figure 2a), Magnetism caused by touch (Figure 2b). As the $\mathrm{S}$ pole touches the $\mathrm{N}$ pole, the other side is an $\mathrm{S}$ pole (Figure 2c). It is a frictional magnetization. When a magnet is rubbed to iron for 5-10 minutes, the iron gets the characteristics of a magnet. Since the S pole of the magnet is rubbed in the figure, the iron bar becomes the opposite pole. It means the N pole (Figure 2d)".

It was revealed that the student teachers who made drawings similar to the sample drawings in the Figure 2 mostly have a misunderstanding in the way that the tip of the iron bar which was firstly touched by a magnet will be polarized in the opposite direction with the friction part of the magnet (CG 74\% and JCLG 56\%). When the students in the research groups identified the temporary magnet poles composed by frictional magnetization, it was seen that they showed poles composed by magnetism with frequent touch. These answers showed that students had conceptual misunderstandings about the processes occurring in magnetization despite knowing the type of temporary magnetization.

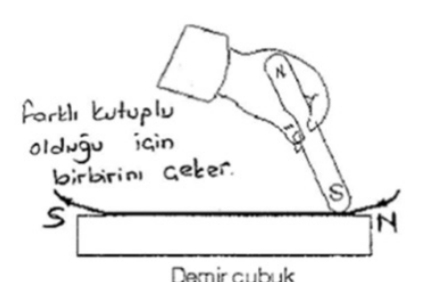

(a)

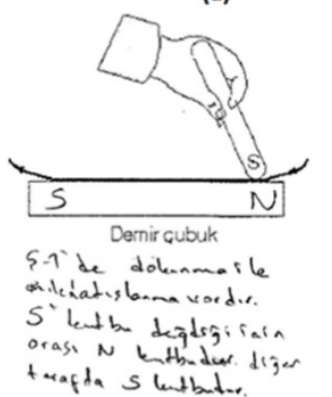

(c)

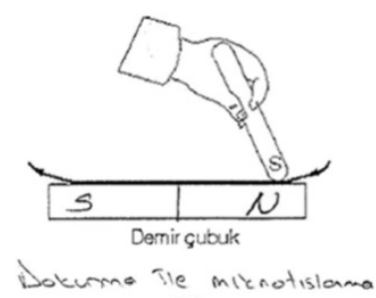

(b)

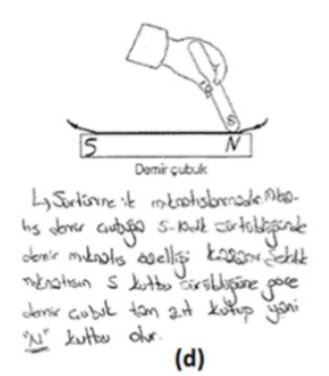

(d)
Figure 2. The drawing samples regarding the wrong representation of student teachers about the frictional magnetization

\section{Discussion and Conclusion}

This section of the study presents the results based upon the research findings regarding the influence of a Jigsaw method based on cooperative learning and a confirmatory laboratory method on the prospective science teachers' achievements of physics in a science teaching laboratory practice course. Also, the misunderstandings of the student teachers on the physics topics in science teaching laboratory practice course were identified.

Although the grade point average (GPA) of the participating student teachers until the sixth semester differed slightly, the findings from the statistical analysis indicated that they had similar characteristics in terms of prior knowledge and overall readiness level. Students' prior knowledge is one of the most important variables that affect their learning. In this regard, having the same prior knowledge level is important in terms of revealing the impacts of the independent variables on dependent variables examined in the current study. For this purpose, following the treatment process in the research groups, the effect of the GPA, which is an indicator of prior knowledge, was controlled in the analysis of the data obtained from the SLPAT that was administered as the post-test. 
According to the findings from analysis, teaching physics in accordance with a Jigsaw method based on cooperative learning revealed a higher level of success than teaching through a confirmatory laboratory method. A confirmatory laboratory approach is known as a traditional method widely used in the laboratory applications of science courses. The results of the studies in the field of science education have proved that Jigsaw method provides a higher performance than traditional methods on students' both the theoretical and experimental learning. The results of this study are in line with the literature $[20,22,24]$. The results of this study regarding the significant effects of Jigsaw method based on cooperative learning on increasing the students' achievements in physics stem from enhancing the cooperative learning efforts of each student by making them responsible for teaching the material to the group members. In addition, students' gathering information in an autonomously and self-adjusted way and making explanations to each other contributed to the positive results of the study. In this way, it could ensure a meaningful set of information through the pieces of information by utilizing what individuals learn from others $[43,46]$. Berger and Hanze [46] stated that oral language is mostly used in the student-student interactions of cooperative learning groups, and this issue affects the process of learning from each other in a negative way. In our study, despite the use of verbal communication in theoretical lessons, experiments were carried out through experiential learning under the guidance of an expert student in each experiment in laboratory practices and in cooperative learning groups. The related literature shows that effective learning occurs in a student-centered learning environment in which students actively participate in the activities conducted through experiential learning [5, 14, 17]. However, a cooperative learning method is not exactly effective in every respect and circumstances for the desired achievements. The research in science education has revealed that cooperative learning is not sufficient to understand especially the topics at microscopic level. In addition, the studies have indicated that if the numbers of topics which are studied in cooperative learning groups are too many, cooperative learning groups will have the same effect as in the traditional methods on learning outputs [38, 40, 46].

As a result of investigating the wrong answers given by the student teachers to the questions, including writing, explaining, drawing and designing the experimental setup, it was determined that the student teachers had some conceptual misunderstandings (see Table 4-10 and Figure 2). It was found out that the student teachers in the research groups had conceptual misunderstandings about sound issues, regarding the sound features and the relationship of these features with each other; concerning the electricity issue, regarding a parallel connection of an electrical circuit to the voltmeter and the causes of the series and the parallel connection of identical batteries used as a generator in an electrical circuit. Furthermore, it was determined that the student teachers had conceptual misunderstandings about the electricity issue on the issue how the brightness of the lamps (the light intensity) will change in an electrical circuit when identical lamps in a series are converted into parallel without replacing the generators. It was seen that students had conceptual misunderstandings in the way that in converting the series connected identical lamps to parallel connection, a lower current will pass through the lamp than series connection as a result of dividing the current into branches although the current in the electrical circuit increases with the decrease of equivalent resistance as the generators are not changed. In addition, it was also ascertained that the student teachers in the research groups had difficulty in determining temporary magnet poles formed in frictional magnetization, and had conceptual misunderstandings. The results of this research revealed that the misunderstandings identified in electricity and magnetism show similarities with those of studies in physics education [11-16]. It was seen that the participating student teachers had conceptual misunderstandings about the causes of the image to be virtual in a plane mirror on the basic light topic. The students tried to explain the fact of the virtual image with reference to the characteristics of a virtual image. However, it was identified that students had misunderstandings in terms of showing the real image of the object on a concave mirror and a convex lens, and the position of the observer and using a screen in order to show the real image. It was found out that the students had similar misunderstandings with those revealed in the previous research on light and optics [3-10].

The related literature emphasizes that traditional confirmatory approach was mostly used for the laboratory applications of science courses. Students work in groups in the applications of the confirmatory laboratory method as it is in the Jigsaw method. However, a special effort is not made for the heterogeneity of the groups in terms of various properties (such as academic achievement) as in the Jigsaw technique. In the experiments performed according to the confirmatory laboratory approach, all the groups conduct the experiments about the same topic at the same time, or each group completes the work by starting from an experiment about a different topic and performing the other experiments one by one throughout the term. In both situations, the students who come to the laboratory for doing experiments experience these experiments almost for the first time. They come to the laboratory with the knowledge gained from the theoretical lessons and the textbooks that describe how these experiments need to be performed. Thus, the students are expected to conduct the experiments in due time, to reach at intended results and to discuss about them [23, 26, 29]. However, it becomes difficult for students to have higher levels of attainment as they do not have enough experiences about these experiments and background information about the theoretical knowledge. In the activities which were carried out through the jigsaw method based on cooperative 
learning and presented in details in the method section of the current study, the students were prepared as the experts of the theoretical knowledge about the experiments and the experiment process. In other words, each group had an expert for all the experiments that would be performed. Each experiment was done under the guidance of an expert (a member of the group). What distinguishes this study from the previous research is that group members provided the expert support for their unexperienced peers in the process of experiments. The findings of the study indicated that the students gained higher levels of achievements in the experiments carried out through the jigsaw method than those done through the confirmatory laboratory method.

It can be difficult for many students to learn physics. Students can develop negative attitudes toward physics and can have various misconceptions. Considering that students become the part of an educational environment with all their prior knowledge and experiences, and new information is built on this prior knowledge, teachers need to have an idea about whether this prior knowledge is compatible with the scientific knowledge or not. In this regard, conceptual misunderstandings identified in this study can provide valuable information for teachers, curriculum developers and textbook authors.

Conducting the current study with prospective science teachers contributed to enhancing their experiences related to the contemporary teaching methods that can be used in the future practices. It will be useful to perform similar studies on different fields and topics of the science curriculum for the pre-service science teachers. With similar efforts, the experiences of prospective science teachers can be enhanced for implementing modern teaching methods in their subject areas during pre-service education. Thus, the continuing professional development of the pre-service science teachers can be supported. In the practices of the present study, the adaptation of the original Jigsaw to science laboratory applications as an alternative to the existing technical literature was enabled. In the case of supporting the results of this study with the similar studies in the future, it can be contributed to create the technique of the "Jigsaw Laboratory".

\section{REFERENCES}

[1] T. Semela. Who is joining physics and why? Factors influencing the choice of physics among Ethiopian university students, International Journal of Environmental and Science Education, Volume.5, No.3, 319-340, 2010.

[2] P. W. Wambugu, J. M. Changeiywo, F. G. Ndiritu. Effects of experiential cooperative concept mapping instructional approach on secondary school students' achievement in physics in Nyeri County, Kenya, Asian Journal of Social Sciences \& Humanities, Volume.2, No.3, 275-296, 2013.

[3] Ö. Anıl, H. Küçüközer. Identifying 9th grader students' previous knowledge and misconceptions about plane mirrors, Journal of Turkish Science Education, Volume.7, No.3, 104-122, 2010

[4] N. Demirci, M. Ahçı. University students' conceptual understanding on the subjects of light and optics, Necatibey Faculty of Education Electronic Journal of Science and Mathematics Education, Volume.10, No.1, 142-181, 2016.

[5] I. Galili, A. Hazan. Learners' knowledge in optics: Interpretation, structure and analysis, Journal of Research in Science Teaching, Volume.22, No.1, 57-88, 2000. http://dx.doi.org/10.1080/095006900290000.

[6] R. Hettmannsperger, A. Mueller, J. Scheid, W. Schnotz. Developing conceptual understanding in ray optics via learning with multiple representations, Zeitschrift für Erziehungswissenschaft, Volume.19, No.1, 235-255, 2016.http://dx.doi.org/10.1007/s11618-015-0655-1.

[7] M. John, J. M. Molepo, M. Chirwa. How do learners conceptualize plane mirror reflection? A case study of grade 11 South African learners, International Journal of Science Education, Volume.13, No.2, 221-230, 2016.

[8] D. Gürel-Kaltakçı, A. Eryılmaz. A content analysis of physics textbooks as a probable source of misconceptions in geometric optics, Hacettepe University Journal of Education, Volume.28, No.2, 234-245, 2013.

[9] S. M. Pompea, E. F. Dokter, C. E. Walker, R. T. Sparks. Using misconceptions research in the design of optics instructional materials and teacher professional development programs, In Tenth International Topical Meeting on Education and Training in Optics and Photonics, International Society for Optics and Photonics, 966515-966515, 2015. http://dx.doi.org/10.1117/12.2207517.

[10] G. Tural. Cross-grade comparison of students' conceptual understanding with lenses in geometric optics. Science Education International, Volume.26, No.3, 325-343, 2015a.

[11] M. Baser. Effects of conceptual change and traditional confirmatory simulations on pre-service teachers' understanding of direct current circuits, Journal of Science Education and Technology, Volume.15, No.5-6, 367-381, 2006.http://dx.doi.org/10.1007/s10956-006-9025-3.

[12] M. F. Cheng, J. L. Lin, Y. C. Chang, H. W. Li, T. Y. Wu, D. M. Lin. Developing explanatory models of magnetic phenomena through model-based inquiry, Journal of Baltic Science Education, Volume.13, No.3, 351-360, 2014.

[13] B. G. Dega, J. Kriek, T. F. Mogese. Categorization of alternative conceptions in electricity and magnetism: The case of Ethiopian undergraduate students, Research in Science Education, Volume.43, No.5, 1891-1915, 2013.http://dx.doi.org/10.1007/s11165-012-9332-z.

[14] T. Gok. The impact of peer instruction on college students' beliefs about physics and conceptual understanding of electricity and magnetism, International Journal of Science and Mathematics Education, Volume.10, No.2, 417-436, 2012. http://dx.doi.org/10.1007/s10763-011-9316-x.

[15] J. Shen, P. C. Gibbons, J. F. Wiegers, A. P. McMahon. Using research based assessment tools in professional development in current electricity, Journal of Science Teacher Education, Volume 18, No.3, 431-459, 2007, http://dx.doi.org/10.1007/s10972-007-9061-8. 
[16] C. R. Smaill, G. B. Rowe, E. Godfrey, R. O. Paton. An investigation into the understanding and skills of first-year electrical engineering students, IEEE Transactions on Education, Volume.55, No.1, 29-35, 2012, http://dx.doi.org/10.1109/TE.2011.2114663.

[17] G. Tural. Active learning environment with lenses in geometric optics, In Asia-Pacific Forum on Science Learning and Teaching, Hong Kong Institute of Education, 10 Lo Ping Road, Tai Po, New Territories, Hong Kong, 2015b.

[18] E. Bilal, M. Erol. Effect of teaching via modeling on achievement and conceptual understanding concerning electricity, Journal of Baltic Science Education, Volume.11, No.3, 236-247, 2012.

[19] F. A. Adeoye. Effects of problem-solving and cooperative learning strategies on senior secondary school students' achievement in physics, Journal of Theory \& Practice in Education (JTPE), Volume.6, No.2, 235-266, 2010.

[20] Z. Tanel, M. Erol. Effects of cooperative learning on instructing magnetism. Analysis of an experimental teaching sequence, Lat. AM. J. Phy. Edu, Volume.2, No.2, 124-136, 2008.

[21] B. R. Wilcox, H. J. Lewandowski. Open-ended versus guided laboratory activities: Impact on students' beliefs about experimental physics, Physical Review Physics Education Research, Volume.12, No.2, 1-8, 2016. http://dx.doi.org/10.1103/PhysRevPhysEducRes.12.020132.

[22] J. C. Colosi, C. R. Zales. Jigsaw cooperative learning improves biology lab course, Bioscience, Volume.48, No.2, 118-124, 1998, http://dx.doi.org/10.2307/1313137

[23] K. Doymus, U. Simsek, A. Karacop. The effects of computer animations and cooperative learning methods in micro, macro and symbolic level learning of states of matter, Eurasian Journal of Educational Research, Volume.36, 109-128, 2009.

[24] Ş. Şen, A. Y1lmaz, Ü. I. Erdoğan. Prospective teachers' views of inquiry-based laboratory activities, Elementary Education Online, Volume.15, No.2, 443-468, 2016. DOI: http://dx.doi.org/10.17051/io.2016.25448.

[25] T. Azuma, K. Nagao. An inquiry into the reproduction of physics-phobic children by physics-phobic teachers, Bulletin of Faculty of Education, Ibaraki University, Volume.56, 91102, 2007.

[26] Y. Karakuyu, İ. Bilgin, A. Sürücü. Effect of inquiry based learning approaches on university students' academic achievement and science process skills in general physics laboratory course, Mustafa Kemal University Journal of Social Sciences Institute, Volume.10, No.21, 237-250, 2013.

[27] B. T. Olufunke. Effect of availability and utilization of physics laboratory equipment on students' academic achievement in senior secondary school physics, World Journal of Education, Volume.2, No.5, 1-7, 2012, http://dx.doi.org/10.5430/wje.v2n5p1.

[28] N. Okur, K. Doymuş. The effects of group investigation and learning together techniques applied in teaching of force and motion subjects on students' academic achievements, Journal of Education Science Research, Volume.2, No.1, 109-123, 2012.
[29] H. Pardhan. Engagement enhance interest in physics, Alberta Science Education Journal, Volume.36, No.2, 25-30, 2004.

[30] R. M. Gillies. Developments in cooperative learning: review of research, Anales de Psicología/Annals of Psychology, Volume.30, No.3, 792-801, 2014.

[31] Y.-M. Huang, Y.-W. Liao, S.-H. Huang, H.-C. Chen. A jigsaw-based cooperative learning approach to improve learning outcomes for mobile situated learning, Educational Technology \& Society, Volume.17, No.1, 128-140, 2014.

[32] V.D. Tran, R. Lewis. The effects of jigsaw learning on students' attitudes in a Vietnamese higher education classroom, International Journal of Higher Education, Volume.1, No.2, 1-13, 2012, http://dx.doi.org/10.5430/ijhe.v $\ln 2 \mathrm{p} 9$.

[33] R. E. Slavin. Cooperative learning and academic achievement: why does groupwork work?, Anales de psicología, Volume.30, No.3, 785-791, 2014.http://dx.doi.org/10.6018/a nalesps.30.3.201201.

[34] J. M. Serrano, R. M. Pons. Introduction: cooperative learning, Anales de Psicología/Annals of Psychology, Volume.30, No.3, 781-784, 2014.

[35] Y. Sharan. Meaningful learning in the cooperative classroom, Education 3-13: International Journal of Primary, Elementary and Early Years Education, Volume.43, No.1, 83-94, 2015, http://dx.doi.org/10.1080/03004279.2015.961723

[36] R. E. Slavin. Cooperative learning in elementary schools, Education 3-13: International Journal of Primary, Elementary and Early Years Education, Volume.43, No.1, 5-14, 2015. http://dx.doi.org/10.1080/03004279.2015.963370.

[37] G. T. Buhr, M. T. Heflin, H. K. White, S. O. PinheiroUsing the jigsaw cooperative learning method to teach medical students about long-term and postacute care, Journal of the American Medical Directors Association, Volume.15, No.6, 429-434, 2014.

http://dx.doi.org/10.1016/j.jamda.2014.01.015

[38] K. Doymus, A. Karacop, U. Simsek. Effects of jigsaw and animation techniques on students' understanding of concepts and subjects in electrochemistry, Education Tech Research Dev, Volume.58, 671-691, 2010. http://dx.doi.org/10.1007/s11423-010-9157-2.

[39] T. Hedeen. The reverse jigsaw: A process of cooperative learning and discussion, Teaching Sociology, Volume.31, No.3, 325-332, 2003. http://dx.doi.org/10.2307/3211330.

[40] A. Karacop, K. Doymus. Effects of jigsaw cooperative learning and animation techniques on students' understanding of chemical bonding and their conceptions of the particulate nature of matter, Journal of Science Education Technology, Volume.22, 186-203, 2013. http://dx.doi.org/10.1007/s10956-012-9385-9.

[41] S. Maden. Effect of jigsaw I technique on achievement in written expression skill, Educational Sciences: Theory and Practice, Volume.11, No.2, 911-917, 2011.

[42] H. Turkmen, D. Buyukaltay. Which one is better? Jigsaw II versus Jigsaw IV on the subject of the building blocks of matter and atom, Journal of Education in Science, Environment and Health (JESEH), Volume.1, No.2, 88-94, 2015.http://dx.doi.org/10.21891/jeseh.43349 
[43] Z. C. Zacharia, N. A. Xenofontos, \& C. C. Manoli. The effect of two different cooperative approaches on students' learning and practices within the context of a WebQuest science investigation, Education Tech Research Dev., Volume.59, 399-424, 2011. http://dx.doi.org/10.1007/s11423-010-91812.

[44] F. Pozzi. Using jigsaw and case study for supporting online collaborative learning, Computers \& Education, Volume.55, No.1, 67-75, 2010.

http://dx.doi.org/10.1016/j.compedu.2009.12.003.

[45] Y. Sharan. Learning to cooperate for cooperative learning, Anales De Psicología, Volume.30, No.3, 802-807, 2014.http://dx.doi.org/10.6018/analesps.30.3.201211.

[46] R. Berger, M. Hänze. Impact of expert teaching quality on novice academic performance in the jigsaw cooperative learning method, International Journal of Science Education, Volume.7, No.2, 294-320, 2015.

http://dx.doi.org/10.1080/09500693.2014.985757.

[47] C. Singh, L. Moin, D. C. Schunn. Introduction to physics teaching for science and engineering undergraduates, Journal of Physics Teacher Education Online, Volume.5, No.3, 3-10, 2010.

[48] A. Surian, M. Damini. "Becoming" a cooperative learner-teacher, Anales de psicología, Volume.30, No.3, 808-817, 2014.

http://dx.doi.org/10.6018/analesps.30.3.201521.

[49] K. Ferguson-Patrick. Developing an inclusive democratic classroom" in action" through cooperative learning, Australian Association for Research in Education, Sydney, New South Wales, 2012. 